\title{
Coparenting and Relationship Satisfaction in Mothers: The Moderating Role of Sociosexuality
}

\author{
Diogo Lamela $^{1} \mathbb{D} \cdot$ Bárbara Figueiredo $^{2} \cdot$ Inês Jongenelen ${ }^{1} \cdot$ Ana Morais $^{1} \cdot$ Jeffry A. Simpson $^{3}$
}

Received: 19 January 2017 / Revised: 2 September 2019 / Accepted: 5 September 2019

(c) Springer Science+Business Media, LLC, part of Springer Nature 2020

\begin{abstract}
This study explored the moderating effect of sociosexual orientation on the association between coparenting alliance/coparenting conflict and relationship satisfaction in mothers in a romantic relationship. Sociosexuality is defined as a personality trait that reflects the individual difference in willingness to engage in uncommitted sexual relations. The study examined a community sample of 635 Portuguese mothers with a monogamous heterosexual relationship. Data on coparenting, relationship satisfaction, and sociosexual orientation were collected. The results revealed the moderating effect of sociosexuality on the significant associations between both coparenting alliance and coparenting conflict predicting relationship satisfaction. For the association between coparenting alliance and relationship satisfaction, mothers with a more restricted sociosexual orientation reported the highest levels of satisfaction when their coparenting alliance was high, but the lowest levels of satisfaction when coparenting alliance was low. For the association between coparenting conflict and relationship satisfaction, mothers with a more restricted sociosexual orientation reported the highest levels of satisfaction when their coparenting conflict was low, but the lowest levels when coparenting conflict was high. Together, the results suggest that especially for women with a more restricted sociosexual orientation, coparenting quality explains significant interindividual variability in relationship satisfaction.
\end{abstract}

Keywords Coparenting $\cdot$ Sociosexuality $\cdot$ Intimacy $\cdot$ Mothers $\cdot$ Women $\cdot$ Relationship satisfaction

\section{Introduction}

Coparenting refers to the mutual and reciprocal involvement of both parents in childrearing (Feinberg, 2003) and comprises two main domains: coparenting alliance and coparenting conflict resolution tactics (Carneiro, CorbozWarnery, \& Fivaz-Depeursinge, 2006; Konold \& Abidin, 2001). Coparenting alliance is defined as the ability of partners to "acknowledge, respect, and value the parenting roles and tasks of the partner" (Cohen \& Weissman, 1984, p. 35), including high levels of support and agreement about child caregiving (Feinberg, 2003; Konold \& Abidin, 2001).

Diogo Lamela

lamela@ulp.pt

1 Digital Human-Environment Interaction Lab, Lusófona, University of Porto, Rua Augusto Rosa 24, 4900-098 Porto, Portugal

2 School of Psychology, University of Minho, Braga, Portugal

3 Department of Psychology, University of Minnesota, Minneapolis, MN, USA
Coparenting conflict resolution tactics, on the other hand, refer to how parents manage their dyadic interaction to provide support to one another during child-related issues or how they solve potential disagreements while coparenting (Krishnakumar \& Buehler, 2000). Coparents may apply assertive or/and destructive conflict tactics to deal with childrelated issues. Destructive coparenting conflict comprises overt-conflict (e.g., belligerence, screaming, threatening, and other angry behaviors) and covert-conflict tactics (e.g., hostility, criticism, blame, and competition) (Lamela, Figueiredo, Bastos, \& Feinberg, 2016).

Previous empirical work has extensively suggested that the optimal coparenting relationship (i.e., high alliance and low destructive conflict between coparents) is one that supports not only children's successful adaptation to the environment, but bolsters marital satisfaction as well (e.g., Le, McDaniel, Leavitt, \& Feinberg, 2016; Umemura, Christopher, Mann, Jacobvitz, \& Hazen, 2015). Despite the quality of coparenting relationships shapes the family's functioning and predicts subsequent relationship outcomes (Zemp, Johnson, \& Bodenmann, 2018), key individual differences relevant to the 
connection between coparenting and relationship functioning have been understudied. Sociosexuality is likely to be one of the key individual differences that significantly explain interindividual variability in romantic relationships (Penke \& Asendorpf, 2008; Simpson \& Gangestad, 1991; Webster et al., 2015). Sociosexuality indexes the degree to which individuals are (versus are not) comfortable engaging in sex in the absence of love or commitment to a partner (Simpson \& Gangestad, 1991), particularly the degree of emotional attachment, intimacy, and commitment that is required before engaging in sexual relations. Individuals with a more restricted sociosexual orientation (many of whom adopt a long-term mating strategy) require higher emotional involvement and a stronger level of commitment, intimacy, and attachment to their potential partners prior to having a sexual relationship, whereas individuals with a more unrestricted sociosexual orientation (many of whom adopt a short-term mating strategy) do not require the same level of emotional bonding and commitment to initiate sexual activities (Penke \& Asendorpf, 2008; Simpson \& Gangestad, 1991).

Sociosexual orientation is being associated not only to the degree to which women rely on male's partners to cooperate and share responsabilities in child nurturing but also with the quality of intimate relationships (Gangestad \& Simpson, 1990; Smith, Jones, \& Allan, 2013). Despite the empirical support for the potential interrelation between coparenting, sociosexuality, and relationship satisfaction, research testing a theory-driven hypothesis of how these constructs may interact is lacking. Toward addressing this gap, the current study sought examine whether sociosexual orientation could moderate the association between coparenting and relationship satisfaction in women involved in romantic relationships.

\section{Coparenting, Relationship Satisfaction, and Sociosexuality}

Research has documented both coparenting domains as significant longitudinal predictors of relationship satisfaction in women (e.g., Fillo, Simpson, Rholes, \& Kohn, 2015; Stanik, McHale, \& Crouter, 2013). Coparenting domains were also associated with other relationship outcomes in women, including sexual satisfaction (Maas, McDaniel, Feinberg, $\&$ Jones, 2018), relationship commitment (McClain, 2011), and relationship stability (Feinberg, Brown, \& Kan, 2012).

Several possible explanations have been offered as to how and why specific characteristics of coparenting relationships might interfere with relationship satisfaction in women. First, perceptions of a positive coparenting alliance, low destructive coparenting conflict, and high conjoint involvement in childcare tasks may be interpreted by women as signs of their partner's commitment to the romantic relationship (Galovan, Holmes, Schramm, \& Lee, 2014). Second, childcare tends to be stressful by nature. In Western countries, the majority of emotional and instrumental childcare tasks are still executed by women (Yavorsky, Kamp Dush, \& Schoppe-Sullivan, 2015). Thus, the quality of the coparenting alliance may serve as a particularly important source of support for women's parenting. A good coparenting alliance is likely to increase women's parenting self-efficacy, subjective well-being, and relationship satisfaction (Abbass-Dick, Stern, Nelson, Watson, \& Dennis, 2015; Le \& Impett, 2015). Third, high partner involvement in the coparenting relationship might reinforce women's investment in choosing a particular partner, including expectations regarding their partner's suitability as a good, investing long-term partner (Gangestad \& Simpson, 2000). This, in turn, might influence women's level of relationship satisfaction (Feldman, 2000). Finally, coparenting conflict (especially chronic conflict) is likely to increase psychological stress and decrease interpersonal trust, emotional availability, and romantic love within relationship dyads (Holland \& McElwain, 2013).

Satisfactory, committed romantic relationships may serve an important evolutionary function to the degree that they enhance children's adaptation to environment (Fletcher, Simpson, Campbell, \& Overall, 2015; Shackelford \& Buss, 1997). From an evolutionary psychological perspective, engagement in committed and long-term romantic relationships is associated with a host of factors (see Buss \& Schmitt, 1993; Fletcher et al., 2015), including a person's sociosexual orientation (Gangestad \& Simpson, 1990, 2000).

Previous empirical research has documented significant associations between sociosexual orientation and several indicators of intimate relationships and parenting-related attributes (see, for example, Simpson, Wilson, \& Winterheld, 2004). For instance, compared to unrestricted females, more restricted women tend to have more stable and committed relationships (Mattingly et al., 2011; Simpson et al., 2004), rate their intimate relationships as more satisfying (Webster et al., 2015), and rate their partners' personal and parenting qualities as more important relative to other features (Simpson \& Gangestad, 1992).

Women who have a more unrestricted sociosexual orientation also tend to value indicators of males' genetic fitness, physical attractiveness, and social dominance relatively more (Pillsworth \& Haselton, 2006). Additionally, they are more likely to have multiple, less committed sexual partners, and they are attracted to males who display "sexy cad" traits (Durante, Griskevicius, Simpson, Cann, \& Li, 2012). Although more restricted women do place some value in men's genetic fitness, they more highly value males' ability and motivation to provide good parental care and investment (Gangestad \& Simpson, 1990). These qualities reflect a partner's reliability as a good, caring long-term partner.

These traits also signal that males are likely to spend relatively more time, energy, and resources on children's caregiving and, therefore, they should be willing to devote 
greater effort to higher quality coparenting. According to parental investment theory (Trivers, 1972), a male's willingness to establish a strong coparenting alliance with his female partner should be one valid indicator of parental investment, which more restricted women may rely on when selecting a partner with whom to maintain a romantic relationship. Surprising little, however, is known about how interindividual variability in sociosexual orientation is associated with perceptions of coparenting, including how both relate to relationship quality in women who are mothers.

The potential value in understanding these associations may find support in previous theoretical work. According to the investment model (Rusbult, 1983), relationship satisfaction depends on the extent to which romantic relationships provide high regards, low costs, and basic expectations are met or surpassed (Rusbult, 1983; Segal \& Fraley, 2016). Coparenting is likely to be evaluated as a reward or a cost, based partially on prior expectations about coparenting relationships and a partner's level of investment in coparenting tasks and parental care (e.g., Altenburger, Schoppe-Sullivan, Lang, Bower, \& Dush, 2014).

Therefore, it is plausible to hypothesize that women with a more restricted sociosexual orientation may have greater expectations regarding the quality of their coparenting relationships for their satisfaction, which is likely to depend on their perceptions of their partners' responsiveness and support in coparenting. Thus, relationship satisfaction might be higher in restricted compared to unrestricted women when they perceive their partners' high involvement and support in coparenting tasks as reflecting partners' commitment and investment in a long-term relationship (Buss \& Schmitt, 1993). However, relationship satisfaction might also be lower in restricted women who perceived poorer coparenting quality since their higher expectations regarding partners' value as a responsive partner and supportive coparent might be violated (Newkirk, Perry-Jenkins, $\&$ Sayer, 2017). Violated coparenting-related expectations signal that women falsely inferred commitment and resources provision from their selected partner (Haselton \& Buss, 2000). Such mistake is costlier for restricted women because it implies the failure of their primary strategy to ensure children's nurturing and their own adaptation. As a result, restricted women might face additional parental efforts to compensate the lack of the expected support at the expense of their relationship satisfaction (Long \& Li, 2019). In contrast, since unrestricted women do not invest in partners' commitment and supportive coparenting as a preferred sexual strategy to ensure children's and their own adaptation, their relationship satisfaction is likely to be less reactive to variations in coparenting quality (Bhogal \& Hughes, 2019).

\section{The Current Study}

Despite the possibility of theoretical ties between coparenting, sociosexuality, and relationship satisfaction in women, no previous research has addressed how these variables interrelate. The primary aim of the current research, therefore, was to test whether sociosexual orientation moderates the relation between coparenting quality and relationship satisfaction. Our study specifically focused on women since the value of coparenting as a strategy to ensure children's care is significantly higher in women than men. This higher female investment in coparenting is partially explained by sex differences in minimal obligatory parental investment (i.e., the parental investment that is minimally required to ensure children's successful adaptation) (Trivers, 1972). Women make a heavier obligatory parental investment (more time, energy, and resource expenditures) than men, to the detriment of directing their resources to other fitness goals, such as their own adaptation or mating opportunities (Goetz \& Shackelford, 2009). Therefore, supportive coparenting relationships may reduce the costs of parental care for women but not for men, due to the differences in type and amount of parental efforts expected to be made by each sex.

The current research examined four hypotheses. First, we hypothesized that women with a more restricted sociosexual orientation (compared to more unrestricted women) should report the lowest levels of relationship (marital) satisfaction when their coparenting alliance was low (Hypothesis 1 ) and their coparenting conflict was high (Hypothesis 2). In addition, women with a more restricted sociosexual orientation should also report the highest levels of relationship (marital) satisfaction when their coparenting alliance was high (Hypothesis 3 ) and their coparenting conflict was low (Hypothesis 4). In other words, more restricted women's satisfaction should be more strongly related to the quality of their coparenting alliance than is true of more unrestricted women.

\section{Method}

\section{Participants and Procedure}

Participants were 635 mothers involved in a monogamous romantic relationship $(72.2 \%$ were married and $27.8 \%$ were cohabitating). Mean age was 39.5 years ( $\mathrm{SD}=6.2$ years). The average length of relationship was 13.29 years ( $\mathrm{SD}=6.8$ years). Their average income was $€ 13,808$ per year $(\mathrm{SD}=€ 764)$. Approximately $33 \%$ of the mothers had completed high school education or less, and $67 \%$ had a college degree.

Data for the current study came from an online survey designed to collect information on mental health, sexual 
behavior, and family functioning in Portuguese women. To participate in the research, participants should be a woman, be 18 years old, and be resident in Portugal. The survey was available on a Portuguese Web site hosted in a university server from March to July of 2015. Participants were recruited via online forums, social media Web sites, and e-mails to institutional public entities Web accounts. The survey took 20-25 min to complete. No financial compensation was provided. To guarantee data quality, standard methodological and ethical guidelines for internet-based research were followed (Kraut et al., 2004). Prior to conducting statistical analyses, data cleaning procedures were performed on the dataset as described by Funk and Rogge (2007). Fifty-two respondents (6.9\%) were eliminated after this procedure: Twenty participants did not meet inclusion criteria (e.g., reported being male or being living outside Portugal) and thirty-two participants did not complete at least $70 \%$ of the assessment protocol. The initial database was comprised of 749 participants.

To participate in the current study, participants were required to be involved in a heterosexual romantic relationship, have at least one child with their current partner, and not any children with any previous partners. If they had more than one child, mothers were asked to rate their coparenting relationship with respect to their youngest child, termed the focal child (average number of children $=1.74, \mathrm{SD}=0.87$ ). The focal children's mean age was 6.5 years $(\mathrm{SD}=4.98$ years; $50.6 \%$ boys $)$. Of the initial sample $(n=749), 114$ mothers were removed because they reported having no child, leaving a final sample of 635 participants. Be involved in a nonheterosexual relationship was also considered as an exclusion criterion because adoption and surrogacy were not legally permitted in Portugal at the time of data collection. However, no participant involved in a non-heterosexual relationship reported to have a child. All research procedures were approved by the institutional review board prior to conducting the study.

\section{Measures}

\section{Coparenting}

Coparenting was measured using the Coparenting Relationship Scale (Feinberg et al., 2012). We used four CRS subscales to examine coparenting relationships: (1) coparenting support (e.g., "My partner makes me feel like I'm best possible parent for our child"), (2) coparenting agreement (e.g., "My partner and I have the same goals for our child"), (3) coparenting undermining (e.g., "My partner sometimes makes jokes or sarcastic comments about the way I am as a parent"), and (4) coparenting conflict (e.g., "Do you argue with your partner about your child, in the child's presence?"). We used these 4 scales to create a total score for coparenting alliance and coparenting conflict domains. The coparenting alliance score was calculated by taking the mean of the 6-item coparenting support and the 4-item coparenting agreement subscales. Similarly, the coparenting conflict score was obtained by taking the mean of the items comprising the undermining (6 items) and conflict (5 items) CRS subscales. Each item was answered on a 7-point scale (from 0 "not true of us" to 6 "very true of us"). Total score for each domain could range from 0 to 6 . Higher scores in each domain reflect greater presence of the assessed coparenting domain. In the current dataset, Cronbach's alpha was .88 for the coparenting alliance domain and .82 for the coparenting conflict domain.

\section{Relationship Satisfaction}

Relationship satisfaction was measured using the 4-item Couple Satisfaction Index (CSI; Funk \& Rogge, 2007). Items on the CSI were derived from widely used marital satisfaction measures. The CSI assesses an individual's satisfaction with their romantic/intimate partner, including happiness ("Please select the answer which best describes the degree of happiness, all the considered, of your relationship"), satisfaction ("In general, how satisfied are you with your relationship"), reward ("How rewarding is your relationship with your partner?"), and warmth and comfort ("I have a warm and comfortable relationship with my partner"). The CSI-4 comprises items with multiple formats and the possible range of scores is $0-21$. Higher scores reflect greater relationship satisfaction $(\alpha=.89)$.

\section{Sociosexual Orientation}

Participants completed the Revised Sociosexual Orientation Inventory (SOI-R; Penke \& Asendorpf, 2008). The SOI-R is a 9-item measure that assesses the predisposition to engage in casual sex. The SOI-R comprises three components assessed by three items each: behavior (e.g., "With how many different partners have you had sex within the past 12 months?"), attitudes (e.g., "Sex without love is ok"), and desire (e.g., "How often do you have fantasies about having sex with someone with whom you do not have a committed romantic relationship?"). The total score was calculated by averaging all items, ranging from 1 to 7 . Low scores reflect a more "restricted" sociosexual orientation (i.e., greater interest in long-term mating strategies), while high scores indicate a more "unrestricted" sociosexual orientation (i.e., greater interest in short-term mating strategies) $(\alpha=.81)$.

\section{Results}

Table 1 presents means and SDs of the main study variables. Preliminary bivariate correlations were first conducted to determine associations between all of the 
variables. Overall, associations were in the expected direction. Means of the main variables were comparable to those found in previous research with samples of Portuguese women, including sociosexual orientation (e.g., Rodrigues \& Lopes, 2017) and coparenting conflict (e.g., Lamela, Jongenelen, Morais, \& Figueiredo, 2017).

To test for the moderating effect of sociosexual orientation on the association between coparenting alliance and relationship satisfaction, and also between coparenting conflict and relationship satisfaction, two independent hierarchical regressions analyses were performed. All variables were first standardized (using $z$ scores) to minimize multicollinearity and achieve more accurate beta weight estimates (Cohen, Cohen, West, \& Aiken, 2003). For both models, relationship satisfaction was treated as the dependent variable. For each regression analysis, participants' age, number of children, and length of relationship were entered as control variables in Step 1. These control variables were included in the models since previous research with women has indicated their significant association with coparenting and/or relationship satisfaction (e.g., Figueiredo \& Conde, 2015; van den Brink, Vollmann, Smeets, Hessen, $\&$ Woertman, 2018). Step 2 included the main effects of the predictor (coparenting alliance or coparenting conflict) and the moderator (sociosexual orientation). Step 3 added the interaction of each predictor and the moderator (i.e., coparenting alliance $\times$ sociosexual orientation or coparenting conflict $\times$ sociosexual orientation). Interactions between each predictor and the moderator were examined using simple slope analyses (Aiken \& West, 1991). Slope difference tests were then computed to probe the two-way interaction effects. Such tests examined whether differences between slopes are significantly different from zero (Dawson \& Richter, 2006).

As presented in Table 2, the hierarchical regression model examining satisfaction with coparenting alliance, sociosexual orientation, and their interaction was significant (after controlling for the covariates), $F(6,629)=35.45$, $p<.001, f^{2}=0.40$. The final model accounted for $28 \%$ of the variance in satisfaction. In Step 3, the explained variance in satisfaction increased with the addition of the interaction term between coparenting alliance and sociosexual orientation $\left(\Delta R^{2}=.014, p<.001\right)$.
Table 2 Moderated hierarchical regression predicting relationship satisfaction from coparenting alliance, and sociosexual orientation

\begin{tabular}{lccccc}
\hline Variable & $B(\mathrm{SE})$ & $\beta$ & $R^{2}$ & $\Delta R^{2}$ & $f^{2}$ \\
\hline Step 1 & & & & & \\
Age & $-0.12(0.05)$ & $-.11^{*}$ & & & \\
Number of children & $0.04(0.04)$ & .05 & & & \\
Length of relationship & $0.03(0.05)$ & .03 & & & 0.01 \\
$F(3,632)$ & 1.91 & & .01 & & \\
Step 2 & & & & & \\
$\quad$ Coparenting alliance & $0.60(0.05)$ & $.54^{* *}$ & & & \\
$\quad$ Sociosexual orienta- & $-0.05(0.04)$ & -.05 & & & \\
$\quad$ tion & & & & & \\
$\Delta F(2,630)$ & $95.6^{* *}$ & & .27 & $.026^{* *} 0.37$ \\
Step 3 & & & & & \\
$\quad$ Coparenting alli- & $-0.12(0.04)$ & $-.12^{* *}$ & & & \\
$\quad \begin{array}{l}\text { ance } \times \text { Sociosexual } \\
\text { orientation }\end{array}$ & & & & & \\
$\Delta F(1,629)$ & $10.2^{* *}$ & & .284 & $0.14 * *$ & 0.40 \\
& & & &
\end{tabular}

$* p<.05 ; * * p<.001$

To interpret these results, the interaction effect between coparenting alliance and sociosexual orientation was next analyzed by plotting satisfaction for women with low $(-1$ $\mathrm{SD})$ and high (+1 SD) coparenting alliance in relation to women with a low/restricted $(-1 \mathrm{SD})$ and a high/unrestricted $(+1 \mathrm{SD})$ sociosexual orientation. The results are shown in Fig. 1. The simple slope tests indicated that despite the fact that the association between coparenting alliance and satisfaction was significant at both high/unrestricted, $B=0.43$ $(\mathrm{SE}=0.06), t=10.96, p<.001$, and low/restricted, $B=0.69$ $(\mathrm{SE}=0.06), t=6.87, p<.001$, levels of sociosexual orientation, this association was stronger among participants with a restricted sociosexual orientation, as predicted.

The second hierarchical regression model predicting satisfaction as a function of coparenting conflict, sociosexual orientation, and their interaction was also significant, $F(6,629)=24.68, p<.001, f^{2}=0.28$ (see Table 3 ). So was the two-way interaction entered at the Step 3 $(\beta=-.09, p<.01)$, which explained additional variance in satisfaction $\left(\Delta R^{2}=.01, p<.01\right)$. Simple slope analyses were then conducted. Figure 2 depicts the significant interaction between coparenting conflict and sociosexual
Table 1 Means, SDs, and bivariate correlations between main study variables

\begin{tabular}{lrlllll}
\hline Variable & M & SD & Range & 1. & 2. & 3. \\
\hline 1. Relationship satisfaction & 14.33 & 4.51 & $1-21$ & - & \\
2. Coparenting alliance & 4.58 & 1.33 & $0-6$ & .48 & - & \\
3. Coparenting conflict & 0.76 & 0.70 & $0-6$ & -.45 & -.64 & - \\
4. Sociosexual orientation & 2.08 & 0.50 & $1-4$ & -.12 & -.15 & .11 \\
\hline
\end{tabular}

All associations were significant at .001. Higher scores reflect greater relationship satisfaction, coparenting alliance, coparenting conflict, and sociosexual orientation 


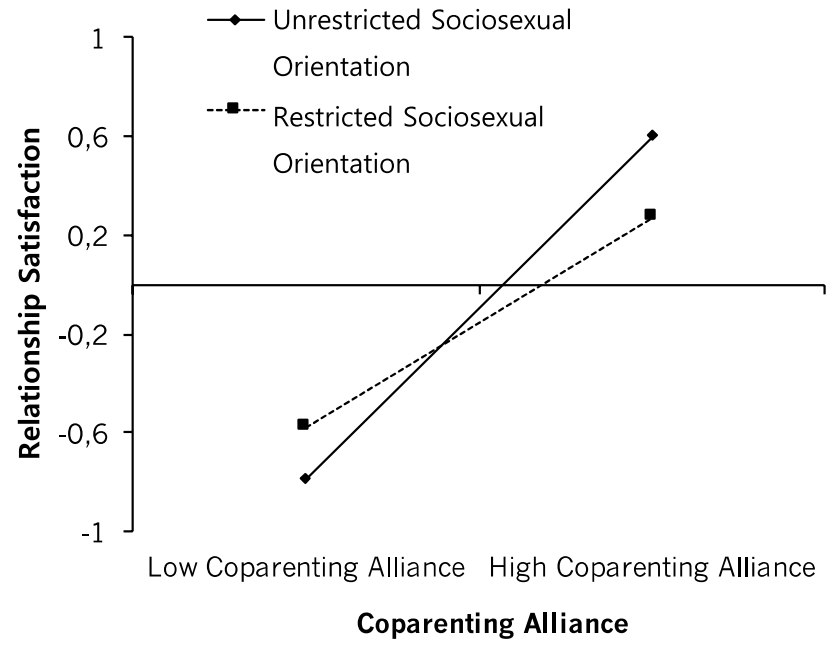

Fig. 1 Interaction between coparenting alliance and sociosexual orientation in predicting relationship satisfaction. Note: All simple slope tests were significant at .001

Table 3 Moderated hierarchical regression predicting relationship satisfaction from coparenting conflict, and sociosexual orientation

\begin{tabular}{|c|c|c|c|c|c|}
\hline Variable & $B(\mathrm{SE})$ & $\beta$ & $R^{2}$ & $\Delta R^{2}$ & $f^{2}$ \\
\hline \multicolumn{6}{|l|}{ Step 1} \\
\hline Age & $-0.09(0.05)$ & -.08 & & & \\
\hline Number of children & $0.03(0.04)$ & .03 & & & \\
\hline $\begin{array}{l}\text { Length of relation- } \\
\text { ship }\end{array}$ & $0.03(0.05)$ & .03 & & & \\
\hline$F(3,632)$ & 1.10 & & .006 & & 0.006 \\
\hline \multicolumn{6}{|l|}{ Step 2} \\
\hline Coparenting conflict & $-0.43(0.04)$ & $-.45^{* * *}$ & & & \\
\hline $\begin{array}{l}\text { Sociosexual orien- } \\
\text { tation }\end{array}$ & $-0.08(0.04)$ & $-.08^{*}$ & & & \\
\hline$\Delta F(2,630)$ & $68.40 * * *$ & & .21 & $.20 * * *$ & 0.27 \\
\hline \multicolumn{6}{|l|}{ Step 3} \\
\hline $\begin{array}{l}\text { Coparenting con- } \\
\text { flict } \times \text { Sociosexual } \\
\text { orientation }\end{array}$ & $0.09(0.04)$ & $-.09 * *$ & & & \\
\hline$\Delta F(1,629)$ & $5.90 * *$ & & .22 & $.01 * *$ & 0.28 \\
\hline
\end{tabular}

orientation predicting satisfaction. Although both simple slopes were negative and differed significantly from zero, coparenting conflict predicted satisfaction more strongly among participants who had a more restricted sociosexual orientation ( $-1 \mathrm{SD}), B=-0.52(\mathrm{SE}=0.06), t=-16.03$, $p<.001$, than in those who had a more unrestricted sociosexual orientation $(+1 \mathrm{SD}), B=-0.34(\mathrm{SE}=0.06)$, $t=-11.04, p<.001$.

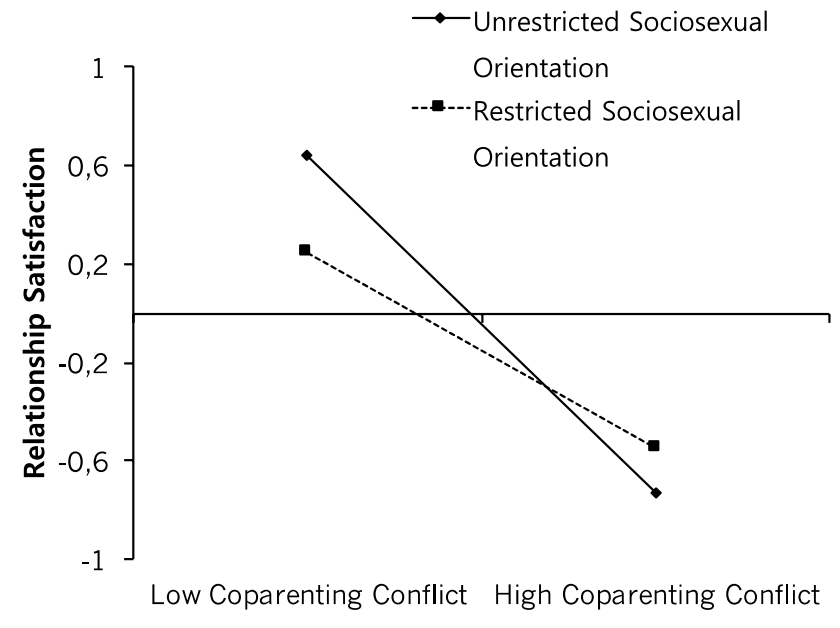

Coparenting Conflict

Fig. 2 Interaction between coparenting conflict and sociosexual orientation in predicting relationship satisfaction. Note: All simple slope tests were significant at .001

\section{Discussion}

The goal of this study was to examine the moderating effect of sociosexual orientation on the association between the quality of coparenting and relationship satisfaction in a large sample of women who were mothers. Moderating effects were tested in two independent models that examined coparenting alliance and coparenting conflict as predictors. In line with previous empirical work (Le et al., 2016; Umemura et al., 2015), the results revealed that both types of coparenting were related to women's satisfaction levels, depending on their sociosexual orientations.

In line with the parental investment theory (Trivers, 1972), our results support for the importance of sociosexual orientation as a key moderator of the association between two coparenting domains and relationship satisfaction. Among women who had a more restricted sociosexual orientation, the associations between coparenting alliance and satisfaction and between coparenting conflict and satisfaction were stronger than was true of women with a more unrestricted orientation (Bhogal \& Hughes, 2019). As predicted, restricted women reported the highest levels of satisfaction when their coparenting alliance was high, but the lowest levels of satisfaction when it was low. These findings are consistent with past research that documented significant variations in relationship satisfaction as a function of perceived coparenting alliance in mothers (Le \& Impett, 2015; Le et al., 2016; Simpson \& Gangestad, 1992). In addition, the same pattern was found for coparenting conflict. Restricted women reported the highest levels of satisfaction when their coparenting conflict was low, but the lowest levels of satisfaction when it was high. These results highlight that coparenting conflict 
is particularly detrimental to relationship satisfaction for women with a restricted sociosexual orientation. Despite these hypotheses were not tested previously, our results in general are consistent with previous research that suggested significant positive associations between a restricted sociosexual orientation and higher relationship satisfaction (e.g., Webster et al., 2015) and also between sociosexual orientation and indicators/cues of parental investment (Mattingly et al., 2011; Rodrigues \& Lopes, 2017; Simpson \& Gangestad, 1991).

These findings are also consistent with the investment model (Rusbult, 1983). Restricted women prefer to invest in long-term, highly committed relationships, in which coparenting quality should operate a major criterion to assess their partner's parental investment in their children. From an evolutionary psychological perspective, committed romantic relationships are viewed as reproductive unions that increase the odds of a child's successful adaptation to environment (Shackelford \& Buss, 1997). Indeed, romantic love, which is strongly associated with commitment, may serve as a commitment device designed in part to sustain long-term pair bonds (Fletcher et al., 2015). This motivation may increase the value of good coparenting, which in turn increases children's successful adaptation to environment (Fletcher et al., 2015).

Based on theoretical work regarding the partners' selection strategies (Buss \& Schimtt, 1993), high coparenting involvement ought to be a valid cue of commitment and investment in a long-term relationship. Thus, the stronger link between coparenting and relationship satisfaction found in restricted compared to unrestricted women is not surprising. Having a good coparenting alliance and low coparenting conflict should also be experienced as rewarding, whereas having poor coparenting alliance and high coparenting conflict should be costly (Simpson et al., 2004). Perceptions of greater coparenting quality among restricted women may indicate that their expectations about their partner's reliability and value as a long-term, responsive partner have been successfully met (Newkirk et al., 2017). This should lead them to evaluate their romantic partner as being highly committed to the family and a good source of social and emotional support, which should increase their relationship satisfaction. Support of this hypothesis was already found in previous research (Altenburger et al., 2014; Holland \& McElwain, 2013).

On the other hand, the lower levels of satisfaction reported by restricted women who perceive a lower coparenting alliance or higher coparenting conflict may be explained by the elevated costs they also perceive (Goetz \& Shackelford, 2009; Long \& Li, 2019). Long-term, committed romantic relationships demand high investment of time and emotional resources (Shackelford \& Buss, 1997), so the expectations of restricted women regarding their partner's value as a responsive partner and supportive coparent should be violated (Lawrence, Nylen, \& Cobb, 2007; Newkirk et al., 2017).

\section{Strengths and Limitations}

Several strengths enhance the contribution of our findings, especially in terms of extending the current literature. First, the current study used highly reliable and valid psychometric measures to assess relationship satisfaction, coparenting, and sociosexuality. This issue is particularly relevant to the coparenting literature, since few theoretically driven measures are available (see Lamela et al., 2016). Second, numerous potential confounding variables were controlled in the current analyses, reducing the likelihood that our findings are spurious or due to third variables. Third, because all participants were in a first romantic relationship, these results cannot be attributable to unmeasured experiences in earlier romantic unions, which can dramatically influence an individual's behavior and expectations in their current romantic relationship (e.g., Whitton, Stanley, Markman, \& Johnson, 2013).

Despite these strengths, our results should be interpreted with caution due to some limitations. First, our study was conducted only with women, none of whom had children with partners other than their current romantic partner. While this homogeneity in participants' relationship history has advantages, it somewhat constrains the generalizability of these findings. In Portugal, similar to the majority of the other high-income countries, separation/divorce and remarriage rates are fairly high, so different patterns of associations might be found in samples of remarried women. Future research should expand the current findings not only to women with more diverse relationship histories but also to men. Second, our theoretical-based hypotheses were tested using correlational data, meaning that causal effects cannot be concluded. Although several variables that could have been responsible for the reported associations were statistically controlled (age, number of children, length of romantic relationship), other possible confounding variables were not controlled. Third, based on the investment model and previous studies addressing expectations about a partner's traits and relationship satisfaction (e.g., Eastwick \& Neff, 2012), we speculated that women's expectations about coparenting may play a role in how sociosexual orientation moderates the effect of coparenting on relationship satisfaction. However, we did not assess women's earlier expectations about coparenting or ideals prior to becoming involved with their partners, so we could not test whether or how such expectations play a role in the current results. Future research should address this issue. Fourth, coparenting was assessed using only self-report measures. Although significant associations have been found between these self-report measures and observational measures of coparenting, observational 
methods could have improved our coparenting assessment and decreased possible shared method variance. An interesting future study should investigate whether mothers with a restricted orientation tend to overestimate or underestimate coparenting relationship quality in relation to their current investment in their relationships.

\section{Conclusion}

Despite these limitations, this study provides empirical evidence regarding the interplay between perceptions of coparenting quality and sociosexual orientation in prediction of relationship satisfaction. Together, the results suggest that especially for women with a more restricted sociosexual orientation, coparenting quality explains significant interindividual variability in relationship satisfaction.

\section{Compliance with Ethical Standards}

Conflict of interest The authors declare they have no conflict of interest.

Ethical Approval All procedures performed in studies involving human participants were in accordance with the ethical standards of the institutional research committee and with the 1964 Helsinki declaration and its later amendments and with Ethical Code of the Portuguese Psychologists Association.

Informed Consent Informed consent was obtained from all individual participants included in the study.

\section{References}

Abbass-Dick, J., Stern, S. B., Nelson, L., Watson, W., \& Dennis, C. L. (2015). Coparenting breastfeeding support and exclusive breastfeeding: A randomized controlled trial. Pediatrics, 135, 102-110. https://doi.org/10.1542/peds.2014-1416d.

Aiken, L. S., \& West, S. G. (1991). Multiple regression: Testing and interpreting interactions. Newbury Park, CA: Sage.

Altenburger, L. E., Schoppe-Sullivan, S. J., Lang, S. N., Bower, D. J., \& Dush, C. M. (2014). Associations between prenatal coparenting behavior and observed coparenting behavior at 9-months postpartum. Journal of Family Psychology, 28, 495-504. https://doi. org/10.1037/fam0000012.

Bhogal, M. S., \& Hughes, S. (2019). Short-term mating. In T. Shackelford \& V. Weekes-Shackelford (Eds.), Encyclopedia of evolutionary psychological science. New York: Springer. https://doi. org/10.1007/978-3-319-16999-6_2238-1.

Buss, D. M., \& Schmitt, D. P. (1993). Sexual strategies theory: An evolutionary perspective on human mating. Psychological Review, 100, 204-232. https://doi.org/10.1037/0033-295x.100.2.204.

Carneiro, C., Corboz-Warnery, A., \& Fivaz-Depeursinge, E. (2006). The prenatal lausanne trilogue play: A new observational assessment tool of the prenatal co-parenting alliance. Infant Mental Health Journal, 27, 207-228. https://doi.org/10.1002/imhj.20089.
Cohen, J., Cohen, P., West, S. G., \& Aiken, L. S. (2003). Applied multiple regression/correlation analysis for the behavioral sciences. London: Routledge.

Cohen, R., \& Weissman, S. (1984). The parenting alliance. In R. Cohen, B. Cohler, \& S. Weissman (Eds.), Parenthood: A psychodynamic perspective (pp. 33-49). New York: Guilford.

Dawson, J. F., \& Richter, A. W. (2006). Probing three-way interactions in moderated multiple regression: Development and application of a slope difference test. Journal of Applied Psychology, 91, 917926. https://doi.org/10.1037/0021-9010.91.4.917.

Durante, K. M., Griskevicius, V., Simpson, J. A., Cantú, S. M., \& Li, N. P. (2012). Ovulation leads women to perceive sexy cads as good dads. Journal of Personality and Social Psychology, 103, 292-305. https://doi.org/10.1037/a0028498.

Eastwick, W. P., \& Neff, A. L. (2012). Do ideal partner preferences predict divorce? A tale of two metrics. Social Psychological and Personality Science, 3, 667-674. https://doi.org/10.1177/19485 50611435941.

Feinberg, M. E. (2003). The internal structure and ecological context of coparenting: A framework for research and intervention. Parenting: Science and Practice, 3, 95-131. https://doi.org/10.1207/ s15327922par0302_01.

Feinberg, M. E., Brown, L. D., \& Kan, M. L. (2012). A multi-domain self-report measure of coparenting. Parenting: Science and Practice, 12, 1-21. https://doi.org/10.1080/15295192.2012.638870.

Feldman, R. (2000). Parents' convergence on sharing and marital satisfaction, father involvement, and parent-child relationship at the transition to parenthood. Infant Mental Health Journal, 21, 176191. https://doi.org/10.1002/1097-0355(200007)21:3<176::AID$\mathrm{IMHJ} 3>3.0 . \mathrm{CO} ; 2-4$.

Figueiredo, B., \& Conde, A. (2015). First- and second-time parents' couple relationship: From pregnancy to second year postpartum. Family Science, 6(1), 346-355. https://doi.org/10.1080/19424 620.2015.1075894.

Fillo, J., Simpson, J. A., Rholes, W. S., \& Kohn, J. L. (2015). Dads doing diapers: Individual and relational outcomes associated with the division of childcare across the transition to parenthood. Journal of Personality and Social Psychology, 108, 298-316. https://doi. org/10.1037/a0038572.supp.

Fletcher, G. O., Simpson, J. A., Campbell, L., \& Overall, N. C. (2015). Pair-bonding, romantic love, and evolution the curious case of homo sapiens. Perspectives on Psychological Science, 10, 20-36. https://doi.org/10.1177/1745691614561683.

Funk, J. L., \& Rogge, R. D. (2007). Testing the ruler with item response theory: Increasing precision of measurement for relationship satisfaction with the Couples Satisfaction Index. Journal of Family Psychology, 21, 572-583. https://doi. org/10.1037/0893-3200.21.4.572.

Galovan, A. M., Holmes, E. K., Schramm, D. G., \& Lee, T. R. (2014) Father involvement, father-child relationship quality, and satisfaction with family work: Actor and partner influences on marital quality. Journal of Family Issues, 35, 1846-1867. https://doi. org/10.1177/0192513x13479948.

Gangestad, S. W., \& Simpson, J. A. (1990). Toward an evolutionary history of female sociosexual variation. Journal of Personality, 58, 69-96. https://doi.org/10.1111/j.1467-6494.1990.tb00908.x.

Gangestad, S. W., \& Simpson, J. A. (2000). The evolution of human mating: Trade-offs and strategic pluralism. Behavioral and Brain Sciences, 23, 573-587. https://doi.org/10.1017/s0140525x000033 $7 \mathrm{x}$.

Goetz, A., \& Shackelford, T. (2009). Sexual conflict in humans: Evolutionary consequences of asymmetric parental investment and paternity uncertainty. Animal Biology, 59, 449-456. https://doi. org/10.1163/157075509X12499949744342.

Haselton, M. G., \& Buss, D. M. (2000). Error management theory: A new perspective on biases in crosssex mind reading. Journal 
of Personality and Social Psychology, 78, 81-91. https://doi. org/10.1037/0022-3514.78.1.81.

Holland, A. S., \& McElwain, N. L. (2013). Maternal and paternal perceptions of coparenting as a link between marital quality and the parent-toddler relationship. Journal of Family Psychology, 27, 117-126. https://doi.org/10.1037/a0031427.

Konold, T. R., \& Abidin, R. R. (2001). Parenting alliance: A multifactor perspective. Assessment, 8, 47-65. https://doi. org/10.1177/107319110100800105.

Kraut, R., Olson, J., Banaji, M., Bruckman, A., Cohen, J., \& Couper, M. (2004). Psychological research online: Report of Board of Scientific Affairs' Advisory Group on the Conduct of Research on the Internet. American Psychologist, 59, 105-117. https:// doi.org/10.1037/0003-066x.59.2.105.

Krishnakumar, A., \& Buehler, C. (2000). Interparental conflict and parenting behaviors: A meta-analytic review. Family Relations, 49, 25-44. https://doi.org/10.1111/j.1741-3729.2000.00025.x.

Lamela, D., Figueiredo, B., Bastos, A., \& Feinberg, M. E. (2016). Typologies of post-divorce coparenting and parental well-being, parenting quality and children's psychological adjustment. Child Psychiatry and Human Development, 47, 716-728. https://doi. org/10.1007/s10578-015-0604-5.

Lamela, D., Jongenelen, I., Morais, A., \& Figueiredo, B. (2017). Cognitive-affective depression and somatic symptoms clusters are differentially associated with maternal parenting and coparenting. Journal of Affective Disorders, 219, 37-48. https://doi. org/10.1016/j.jad.2017.05.006.

Lawrence, E., Nylen, K., \& Cobb, R. J. (2007). Prenatal expectations and marital satisfaction over the transition to parenthood. Journal of Family Psychology, 21, 155-164. https://doi. org/10.1037/0893-3200.21.2.155.

Le, B. M., \& Impett, E. (2015). The rewards of caregiving for communally motivated parents. Social Psychological and Personality Science, 6, 758-765. https://doi.org/10.1177/1948550615 581498.

Le, Y., McDaniel, B. T., Leavitt, C. E., \& Feinberg, M. E. (2016). Longitudinal associations between relationship quality and coparenting across the transition to parenthood: A dyadic perspective. Journal of Family Psychology, 30, 918-926. https:// doi.org/10.1037/fam0000217.

Long, M. L., \& Li, N. P. (2019). Violation of long-term mate preferences. In T. Shackelford \& V. Weekes-Shackelford (Eds.), Encyclopedia of evolutionary psychological science. New York: Springer. https://doi.org/10.1007/978-3-319-16999-6_3720-1.

Maas, M. K., McDaniel, B. T., Feinberg, M. E., \& Jones, D. E. (2018). Division of labor and multiple domains of sexual satisfaction among first-time parents. Journal of Family Issues, 39, 104-127. https://doi.org/10.1177/0192513x15604343.

Mattingly, B. A., Clark, E. M., Weidler, D. J., Bullock, M., Hackathorn, J., \& Blankmeyer, K. (2011). Sociosexual orientation, commitment, and infidelity: A mediation analysis. Journal of Social Psychology, 151, 222-226. https://doi.org/10.1080/00224 540903536162.

McClain, L. R. (2011). Better parents, more stable partners: Union transitions among cohabiting parents. Journal of Marriage and Family, 73, 889-901. https://doi.org/10.1111/j.1741-3737.2011.00859.x.

Newkirk, K., Perry-Jenkins, M., \& Sayer, A. G. (2017). Division of household and childcare labor and relationship conflict among low-income new parents. Sex Roles, 76, 319-333. https://doi. org/10.1007/s11199-016-0604-3.

Penke, L., \& Asendorpf, J. B. (2008). Beyond global sociosexual orientations: A more differentiated look at sociosexuality and its effects on courtship and romantic relationships. Journal of Personality and Social Psychology, 95, 1113-1135. https://doi. org/10.1037/0022-3514.95.5.1113.
Pillsworth, E. G., \& Haselton, M. G. (2006). Male sexual attractiveness predicts differential ovulatory shifts in female extrapair attraction and male mate retention. Evolution and Human Behavior, 27, 247-258. https://doi.org/10.1016/j.evolhumbeh av.2005.10.002

Rodrigues, D., \& Lopes, D. (2017). Sociosexuality, commitment, and sexual desire for an attractive person. Archives of Sexual Behavior, 46, 775-788. https://doi.org/10.1007/s10508-016-0814-3.

Rusbult, C. E. (1983). A longitudinal test of the investment model: The development (and deterioration) of satisfaction and commitment in heterosexual involvements. Journal of Personality and Social Psychology, 45, 101-117. https://doi. org/10.1037/0022-3514.45.1.101.

Segal, N., \& Fraley, R. C. (2016). Broadening the investment model: An intensive longitudinal study on attachment and perceived partner responsiveness in commitment dynamics. Journal of Social and Personal Relationships, 33, 581-599. https://doi. org/10.1177/0265407515584493.

Shackelford, T. K., \& Buss, D. M. (1997). Marital satisfaction in evolutionary psychological perspective. In R. Sternberg \& M. Jojjat (Eds.), Satisfaction in close relationships (pp. 7-25). New York: Guilford.

Simpson, J. A., \& Gangestad, S. W. (1991). Individual differences in sociosexuality: Evidence for convergent and discriminant validity. Journal of Personality and Social Psychology, 60, 870-883. https://doi.org/10.1037/0022-3514.60.6.870.

Simpson, J. A., \& Gangestad, S. W. (1992). Sociosexuality and romantic partner choice. Journal of Personality, 60, 31-51. https ://doi.org/10.1111/j.1467-6494.1992.tb00264.x.

Simpson, J. A., Wilson, C. L., \& Winterheld, H. A. (2004). Sociosexuality and romantic relationships. In J. Harvey, A. Wenzel, \& S. Sprecher (Eds.), Handbook of sexuality in close relationships (pp. 87-111). Mahwah, NJ: Erlbaum.

Smith, D. S., Jones, B. C., \& Allan, K. (2013). Socio-sexuality and episodic memory function in women: Further evidence of an adaptive "mating mode". Memory \& Cognition, 41, 850-861. https://doi.org/10.3758/s13421-013-0301-1.

Stanik, C. E., McHale, S. M., \& Crouter, A. C. (2013). Gender dynamics predict changes in marital love among African American couples. Journal of Marriage and Family, 75, 795-807. https:// doi.org/10.1111/jomf.12037.

Trivers, R. L. (1972). Parental investment and sexual selection. In B. Campbell (Ed.), Sexual selection and the descent of man (pp. 136-179). New York: Aldine de Gruyter.

Umemura, T., Christopher, C., Mann, T., Jacobvitz, D., \& Hazen, N. (2015). Coparenting problems with toddlers predict children's symptoms of psychological problems at age 7. Child Psychiatry and Human Development, 46, 981-996. https://doi.org/10.1007/ s10578-015-0536-0.

van den Brink, F., Vollmann, M., Smeets, M. A. M., Hessen, D. J., \& Woertman, L. (2018). Relationships between body image, sexual satisfaction, and relationship quality in romantic couples. Journal of Family Psychology, 32(4), 466-474. https://doi. org/10.1037/fam0000407.

Webster, G. D., Laurenceau, J.-P., Smith, V., Mahaffey, A. L., Bryan, A. D., \& Brunell, A. B. (2015). An investment model of sociosexuality, relationship satisfaction, and commitment: Evidence from dating, engaged, and newlywed couples. Journal of Research in Personality, 55, 112-126. https://doi.org/10.1016/j. jrp.2015.02.004.

Whitton, S. W., Stanley, S. M., Markman, H. J., \& Johnson, C. A. (2013). Attitudes toward divorce, commitment, and divorce proneness in first marriages and remarriages. Journal of Marriage and Family, 75, 276-287. https://doi.org/10.1111/ jomf.12008. 
Yavorsky, J. E., Kamp Dush, C. M., \& Schoppe-Sullivan, S. J. (2015). The production of inequality: The gender division of labor across the transition to parenthood. Journal of Marriage and Family, 77, 662-679. https://doi.org/10.1111/jomf.12189.

Zemp, M., Johnson, M. D., \& Bodenmann, G. (2018). Within-family processes: Interparental and coparenting conflict and child adjustment. Journal of Family Psychology, 32, 299-309. https ://doi.org/10.1037/fam0000368.
Publisher's Note Springer Nature remains neutral with regard to jurisdictional claims in published maps and institutional affiliations. 